\title{
TOWARDS A TRANSFORMATIVE AND HOLISTIC CONTINUING SELF-DIRECTED LEARNING THEORY
}

\author{
C. du Toit-Brits \\ Department of Curriculum Studies, Philosophy and Research \\ North-West University \\ Potchefstroom, South Africa \\ e-mail: charlene.dutoit@nwu.ac.za
}

\section{ABSTRACT}

This article encompasses the theoretical motivation for a proposed self-directed learning (SDL) theory by means of a literature review of SDL and the presentation of the anticipated theory/model. Over the previous decades, SDL has been an active area of inquiry in adult education and learning. Several efforts have been made to construct models/theories so as to assist in elucidating the notion and foundations of SDL. Therefore, for purposes of this article the author will present another conceptual model and description/definition of SDL to bring to the fore the intricacy of SDL, based on my enhanced understanding. This model proposes yet another understanding of SDL.

Key words: control, learning, students, learning environment, teachers, self-directed learning, self-directedness.

\section{INTRODUCTION}

Throughout the previous decades, SDL has been a dynamic area of enquiry in adult education and learning. Numerous scholarships have acknowledged tendencies in this body of scholarships like its definition, approaches, utilization and SDL's impact to the individual student since 1960s (Andruske 2009; Brockett et al. 2001; Brockett and Hiemstra 1991; Caffarella 1993; Candy 1991; Conner et al. 2009; Garrison 1997; Kirk et al. 2012; Knowles, Holton III and Swanson 2015; Knowles 1975).

Despite the fact that educators work at linking learning from old-style professional development courses to the reality of their work in their classroom, other learning models offer opportunities to empower them to do just that. SDL is one such a model. SDL suggests that teachers need to be granted opportunities within the classroom to select, design, assess and implement their own individual learning in their teaching space. SDL in itself is a way of life and individuals therefore need to partake in SDL activities outside the formal education/training classroom environments (Du Toit-Brits 2015; Kember and Leung. 2009; Khiat 2015; Ramsden 2003; Abuhamdeh and Csikszentmihlyi 2012). Achievement in any undertaking is grounded on 
an amalgamation of willingness, self-direction, aptitude, accountability and attitudes. SDL is the manner in which individuals obtain new and first-hand understanding, awareness, thoughts, skills, attitudes, and experience (Guglielmino 2013; Guglielmino 2008; Gabrielle, Guglielmino and Guglielmino 2006; Knowles, Holton III and Swanson 2015).

Several terminologies have been conceived for describing SDL. These terminologies include “autonomous learning”, “independent learning”, "lifelong learning”, "self-direction in learning”, "self-initiated learning”, "self-plan learning”, and "self-teaching” and have become related to SDL (Biggs and Tang 2011; Chang 2012). Due to the use of numerous terms it has made describing SDL a challenging process (Brockett and Hiemstra 1991; Candy 1991; Hiemstra 1994; Hiemstra and Sisco 1990; Holt 2011; Merriam, Caffarella and Baumgartner 2007). It is however mistaken to see individuals as fundamentally self-directed learners for the reason that SDL is a compound development that necessitates individuals to take the initiative for thinking about their learning goals which is imperative to improve their academic performance (Du Toit-Brits and Van Zyl 2017; Guglielmino 1978). To succeed in their learning goals, individuals (students) have to diagnose and identify their own learning needs and formulate new goals for their learning. Regardless of the many meanings attached to SDL, it is worthwhile to reflect on some explanations of SDL that have been formulated by noteworthy authors in the arena of SDL.

\section{EXPLANATION AND THE HISTORICAL FOUNDATION OF SDL}

Knowles recognises the wide-ranging scope of SDL in his explanation of what SDL all entails. He specified that SDL is a: "process in which individuals take the initiative, with or without the help of others, in diagnosing their learning needs, formulating learning goals, identifying human and material resources for learning, choosing and implementing appropriate learning strategies, and evaluating learning outcomes” (Knowles 1975, 18). Allen Tough uses the concept selfteaching and defines it as "the assumption of the learner for planning and directing the course of learning” (Brookfield 1993, 229). As seen from the explanation of Knowles and Tough, the accountability positions the student to take responsibility for the learning process. What is important about Knowles' explanation of SDL is that SDL can be adopted "with or without the help of others" (Knowles 1975, 18).

Yet another author in the field of SDL is Peters and he explains how he perceives SDL as follows: “A process in which the learner makes a decision to learn in order to achieve a goal, formulates a plan to reach the goal, and takes action toward the goal ... Self-direction means that the learner has control over the process of goal setting, planning, and action” (Peters 1989, 43). In Peters' explanation he emphasises effective control between the student and an outside 
agent. Hence, when the student controls the learning process, it can be viewed as being a SDL process. When the student does not have control over the learning process, but the outside agent does, it can no longer be viewed as a self-directed process. The "self" of the student should be vested in the student's own learning process so that when this takes place, the student is enabled to adjust to new situations in the learning process; hence to be empowered to take responsibility for lifelong learning (Canipe and Fogerson 2006; Du Toit-Brits 2015).

Another outlook on SDL is that of Caffarella $(1993,25)$ in that he states that SDL is a selfinitiated process of learning whereby the ability of individuals to plan and manage their own learning comes to the fore. The characteristics of the student need to focus on personal autonomy whereby he/she establishes education in formal settings, which allows for better student control. Also in Caffarella's explanation the focus is centred on balancing control. It is also Candy's (1991) opinion that the idea of control is seen to be existing on a continuum. Long's (1998) view of SDL involves the student seeking independent learning. Other explanations of SDL (Garrison and Baynton 1987; Garrison 1997) consider the external environment of the student in which the student needs to facilitate social change. Student/learner autonomy can be seen as taking ownership of responsiveness to learning. Within this understanding of SDL the necessity arises for the students to apply their awareness to act against the authoritarian attentiveness of others (Brookfield 2005; Oddi, Ellis and Roberson 1990; Owen 2002). Two other researchers, namely Hammond and Collins (1991), integrate critical theory into the Knowles definition and rename it to "Critical SDL", meaning "learners take the initiative, with the support and collaboration of others, for increasing selfand social awareness and critically analysing and reflecting on their situations” (Hammond and Collins 1991, 13).

The conclusions one can draw from reviewing the above literature is that SDL is not a new concept; writers have been writing about SDL since the early 1960s. A Wide range of perspectives and models within the literature pertaining to SDL has been written up and needs to be borne in mind, and specifically now for purposes of this article. From an extensive study on the different explanations of SDL the author has come to understand that it is unreasonable to articulate an explanation of SDL that would be so comprehensive as to contain all examples in which the term (acronym) SDL has been used. All these different explanations were developed to describe the intricacy of SDL and to comprehend the progress of students' selfdirection in learning. Throughout these different explanations / models the thought of SDL has placed students in the heart of learning in that the students' self-direction in learning and their willingness to be self-directed are accentuated. This is vital to the success of the learning process; therefore cultivating students' self-direction in learning is an imperative result of 
education (Du Toit-Brits 2015; Knowles, Holton III and Swanson 2015).

In the following section of this article the author will present yet another conceptual model and explanation of SDL to bring to the fore the intricacy of SDL, based on my enhanced understanding. The next section of this article starts off by means of a brief description of the author's proposed Transformative and Holistic Continuing Self-Directed Learning (THCSDL) theory. This is followed by a presentation of the model and concludes with possible implications.

\section{PRESENTATION OF A TRANSFORMATIVE AND HOLISTIC CONTINUING SELF-DIRECTED LEARNING THEORY}

SDL can be seen as an active process of meaning-making (Wenger 1998). Meaning-making is the result of critical reflection on learning expectations which can lead to open minds that embrace transformation (Mezirow 2000). To give meaning to teaching and learning (education), the student is not a passive receiver of information; rather an active and selfdirected contributor in the learning process, working to create a meaningful understanding of the learning information found in the learning environment. Learning needs to emphasise personal growth, with the focus on learning as belonging, learning as becoming, learning as experiencing and learning as doing (Wenger 1998; Wertsch 1985). Learning needs to emphasise personal growth, and education needs to connect to students' lives, emotions and learning experiences (Johnson 2012) so that they can reach their full potential (selfactualization).

The author is of opinion that the worldview of SDL needs to strive to apply the principle of wholeness; that the prerequisite of SDL is to include the human experiences of the student/teacher in the teaching- and learning context. This involves using SDL contents to create intrapersonal, interpersonal and interconnections. SDL needs to enable students to discover and become conscious of their full potential. As a consequence, SDL needs to be of a transformative and holistic nature, meaning that students need to be exposed to a body of knowledge, they need to reflect on their experience (their thoughts and feelings), and thereby give meaning to their learning experience so that the SDL process can lead to transformation (holism).

Hence the focus for this model is to investigate features influencing the holistic growth (wholeness) of students' self-directedness. In literature it has been debated that students' selfdirection in learning is a result of the interaction among and interrelatedness of students' personal characteristics and the learning environment (Brockett 1994; Candy 1991; Guglielmino 2008; 2013; Knowles, Holton III and Swanson 2015). Yet a number of other 
authors in SDL all are of opinion that students' self-direction in learning relates to their intrinsic motivation (Brookfield 1993; Du Toit-Brits and Van Zyl 2017; Garrison 1997; Pappas 2013; Rager 2004) and teachers' facilitation strategies (Andruske 2009; Du Toit-Brits 2015; Grow 1991). These aspects are consistent with those contained in the model presented. This model suggests that students' individual learning characteristics, the learning environment, compounded with a meaning-making learning change process can change students into holistically transformed self-directed lifelong goal-oriented students. These key factors and their theorised connections will be elucidated on in the succeeding paragraphs. The conceptual model is offered schematically in Figure 1.

Students' Individual Learning

Characteristics

- Student motivation

- Performance goals

- Intrinsic and extrinsic goals

- Self-directed Learning Ability

- Self-awareness of own learning needs

\section{Teaching and Learning} Environment

- Good teaching purpose

- Emphasis on independence

- Teacher's attitude towards SDL

- Teacher's engagement with SDL

- Relatedness - sense of belonging

- Sense of autonomy

- Agent of own learning

- Learner's capacity to learn

(knows how to learn)

- Ownership through empowerment

Transformative and Holistic Continuing SDL

- SDL readiness

Learning: Meaning-Making process

- Self-engaged learning (putting the "self" in learning)

- Holistic learning approach

- SD Continuing approach to teaching and learning

- Learning as belonging, learning as becoming, learning as experiencing and learning as doing

- SDL competence

- Identity Change

- Attitudinal Change

- Behavioral Change

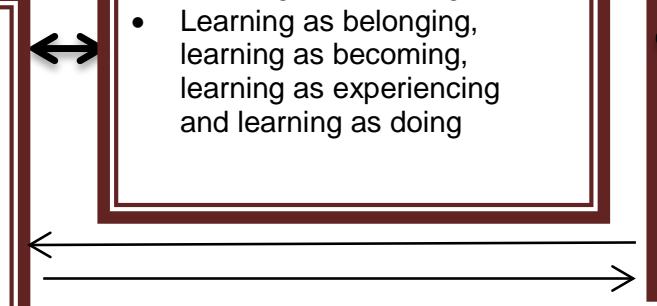

Self-directed Lifelong

Goal-Oriented Students

Figure 1: Transformative and Holistic Continuing Self-Directed Learning theory (THCSDL) (Du ToitBrits)

\section{Students' individual characteristics}

In the proposed version of the THCSDL model (theory), the author of this article suggested five 
varieties of students' individual characteristics, namely SDL ability, student motivation, performance goals, intrinsic and extrinsic goals and self-awareness of own learning needs. The five aspects of students' individual characteristics indicated above can be seen to be some of the key features influencing and stimulating the development and growth of students' selfdirectedness.

Students' motivation to learn in a self-directed manner may derive from their intrinsic and extrinsic goals pertaining to the act of performing learning tasks and while they are engaging in SDL tasks, they are likely to set performance goals. These performance goals are also believed to influence students' learning motivation, their ways of thinking, their effort, their behaviours and their attitude during the SDL process. With regard to students' learning motivation it may also refer to students' willingness to learn in a more self-directed manner, which would stem from their curiosity about the learning tasks.

Students' adoption of higher-performance goals, such as short-term motivation and objectives, is attributed to their reasons for learning, which are to demonstrate their SDL ability. This phenomenon of students adopting higher-performance goals such as short-term motivation and objectives is attributed to their reasons for learning, which also are to demonstrate their SDL ability. More motivated students will set higher performance goals, which can lead to a higher level of self-awareness of own learning needs; hence gaining more pleasant results such as a stronger SDL ability and capability. I believe that students' endorsement of performance goals may furthermore influence their adoption of SDL skills; therefore, it is suggested that students with a higher-performance goal orientation may be more likely to apply SDL skills that may subsequently result in transformed lifelong SDL.

Associations between student motivation and performance goals can be evident in a classroom where students and teachers adopt SDL strategies and SDL skills. Students' performance-goal orientation and their attachment to relations with learning attitudes and willingness to tackle self-directed tasks can lead to the effective application of SDL skills such as self-monitoring, help-seeking, curiosity, self-management and taking responsibility for their own learning. Students with higher intrinsic and extrinsic performance goals and motivation levels tend to be more adaptive to positive learning attitudes and SDL. These students can consequently demonstrate an ability to self-engage in their learning and to be more self-aware of their own learning needs.

When students are motivated by their desire to learn and expect from themselves to be able to master the required knowledge and skills, they are more likely to adopt the SDL approach to enhance their understanding, to make meaning of their learning, to develop autonomous thinking and to become more self-confident in their learning attempts. It is further 
the author's opinion that students' performance-, intrinsic and extrinsic goals may directly or indirectly influence their self-directedness.

For example, these goal-oriented students may prefer using self-planning and selfmonitored learning strategies, which lead to self-directedness in learning. Such preferences may inspire students to be self-efficient, self-modifying, self-determined, independent and autonomous in their learning, which in turn contributes to the development and strengthening of self-directedness. Furthermore, a student that is higher-performance, intrinsic and extrinsic goal-oriented can be more motivated and more interested in the learning tasks. Such interest and curiosity may lead to profound participation in learning tasks, which may additionally enhance these specific students' sense of control over their own learning, and enhance their self-directedness.

As a result, this proposed theory/model suggests that students' performance-, intrinsic and extrinsic goal orientation is associated (negatively or positively) with the extent of SDL willingness to make concerted inputs during their learning journey to where they finally reach their inner-personhood, which is motivation, and goal orientation is associated with better selfdirectedness. Leading from the fore-going exposition of students' individual characteristics, the skills they need to acquire are set out as follows: willingness to learn, self-management of learning, personal autonomy related to learning, anticipatory schemes, skills pertaining to learning and thinking, subject-matter autonomy, metacognitive skills and a sense of personal control. Thus in summary, it can be said that self-directedness is a personal attribute by means of which students apply SDL to emphasise their personal growth as a whole, while focusing on learning as belonging, learning as becoming, learning as experiencing and learning as doing.

\section{The teaching- and learning environment}

The second set of factors in this proposed Transformative and Holistic Continuing SelfDirected Learning theory, which also proposes to influence students' transformation into being self-directed lifelong goal-oriented students, is the teaching- and learning environment. The author is of opinion that a change in teaching- and learning methods may influence students' approaches and outcomes attached to SDL. Research has maintained the reality of an association between teachers' teaching strategies and students' approaches to the act of performing learning tasks (Entwistle 1991; Gow and Kember 1993; Trigwell and Prosser 1996; Trigwell, Prosser and Waterhouse 1999). The strategies students follow in their learning attempts can depend on their perceptions of specific learning circumstances. Students may demonstrate certain SDL skills in one learning circumstance, but not necessarily in the next encountered learning circumstance. What is more, in a similar learning environment, in which 
the setting/background and strategy of teaching may be the same for all students, students' abilities (SDL abilities), motivation and goal orientation within that context may be different. Since not all students have reached or are at the same stage in the SDL continuum, the teacher needs to take it into account while conveying facts or setting tasks.

A number of key elements within the teaching- and learning environment are considered significant regarding student's self-directedness in learning, namely good teaching purpose associated with SDL materials, teachers' constructive attitudes towards SDL and teachers' engagement with SDL in their teaching. The author is thus of opinion that if the abovementioned aspects prevail in the learning environment, students can be (a) competent to control and master SDL in the learning environment, and the learning outcomes; (b) students will have a need for a close and affectionate relationship with other students and teachers whom they can relate to during the SDL development learning process; (c) students will have a sense of autonomy and freedom and (d) students will have a sense of belonging within the learning environment where they can control their SDL development process. This can cultivate an emphasis on independence in learning, which in turn will influence students' self-directedness in learning with the focus on learning as belonging, learning as becoming, learning as experiencing and learning as doing.

Teachers who put into practice these afore-mentioned elements, namely good teaching purpose, emphasis on independence, constructive attitude towards SDL and being a practitioner of SDL themselves can create learning conditions in the learning environment that will aim at enhancing students' motivation to take ownership of their learning. Students need to feel autonomous and competent, and for them to achieve this, and consequently self-directedness in their learning, the social-contextual factors within the learning environment need to promote these feelings of autonomy, competence and ownership. Students' learning performance will be maximized when teachers and students set specific SDL goals that have high valence and equally enhanced when students understand which behaviours will lead to setting learning goals that will result in them feeling competent and empowered to implement those behaviours.

Having said the above, the authors' outlook further is that the SDL environment climate needs to (a) install trust; (b) provide opportunities for students to ask questions; (c) provide a connected classroom community; (d) make learning personal; (e) let SDL be constantly modelled; (f) install a sense of belonging; (g) create opportunities for students to engage in what is being taught; (h) provide motivation to learn, and (i) encourage commitment in students to the development of SDL skills. These aspects mentioned can be seen as pillars on which students can develop into owners of their learning.

Further to this, the author concludes that learning environments can influence students' 
adoption of SDL skills and outcomes. Good teaching, teachers' attitudes towards SDL, teachers' engagement with SDL, relatedness, cultivation, realisation, emphasis on independence and clear goals and standards are important and encouraging predictors of students becoming empowered to take ownership of their learning so that they can know how to learn (students' capacity to learn) and to be agents of their own learning. The learning environment is as a result an important feature and can influence students' development of SDL skills as well as their satisfaction with their SDL experiences, resulting in them feeling responsible for their own learning in order for them to experience progress and success. When teaching- and learning environments are attentive to the above-mentioned elements, students perceive their learning environment to be positive which can lead to them becoming more likely to also adopt SDL. In addition to this, the author's viewpoint is that teachers' attitudes towards SDL as well as their engagement with SDL within the learning environment are strong predictors of whether or not students will choose to apply SDL skills and therefore also be transformed into self-directed lifelong goal-oriented students.

From the exposition above, the author has identified a number of elements/aspects in a teaching- and learning environment that may be promising or discouraging to students' selfdirectedness in learning. A learning climate which grants students opportunities of taking responsibility for and ownership of their learning, is but one of the selection of learning topics that encourages SDL and enables students to learn to take control of their own learning. The above-mentioned elements will support the development and progress of students' selfdirectedness within the learning process. Thus an SDL environment in which learning is meaningful should be grounded in SDL with sufficient support.

\section{Learning: A meaning-making process}

In this article, the author proposed that the self-directedness of students is a vital result of students taking responsibility for and ownership of their own learning by means of which students become capable of learning; thus know how to learn. Concomitant with the abovementioned, teachers in the learning environment need to project a positive attitude towards fostering SDL skills within each student's capacity so that learning can be experienced as personal and meaningful. Educators need to create opportunities for support and guidance to be available to those students that are emotionally and academically not prepared to deal with SDL within this learning process to which a teacher wishes to give "meaning to learning”. A learning environment in which "learning is meaningful” needs to be grounded in SDL with relevant emotional and social support and guidance. The author is of opinion that students' selfdirectedness can also be determined by the learning process which needs to be a "meaning- 
making” learning-change process. This meaning-making learning change process needs to stress a holistic learning development approach so that these students become acquainted to deep-level processing, and deep-level learning. In this holistic meaning-making learning change process learning should be directed at developing students' abilities to make learning meaningful so that the "self" (self-engaged learning - putting the "self" in learning) in the student can be totally (identity, attitudinal, behaviour-wise) developed and transformed.

Hence the author of this current article maintains that in this meaning-making learning process, educators need to (a) set the foundation for SDL; (b) provide on-going support; (c) provide tools for supporting self-managed learning; (d) construct a co-operative learning environment in which they assist in enhancing the students' learning experiences; (e) facilitate students' initiatives regarding SDL, (f) rather assist as mentors than act as instructors and (g) to be able to take different contextual factors into consideration in which SDL might be promoted. Teachers need to be aware of the impact of the environments (cultural, educational and emotional) of students on SDL and the potential it has to empower ALL students when applying SDL in learning. The recognition by educators that students are coming from diverse backgrounds and that these backgrounds can influence the SDL preparedness of students (Du Toit-Brits 2015; Entwistle and Entwistle 1997) in the learning process, and if SDL is effectively employed by educators, then SDL can be seen as the opening of the doors of meaningful learning.

In light of the implicit expectations placed on teachers as seen above, the author is mindful that due attention would need to be given to teacher training programmes offered to teacherstudents - in other words, are current teacher training programmes geared towards SDL? The author is mindful that educational institutions should construct chances within their teachinglearning environments for practicing self-direction in learning in order for teacher-students to be capable to become accustomed to different and innovative circumstances continually by discovery, handling and using information meritoriously when carrying out learning tasks. Teacher-students should be supported not simply to pass exams, but to grow and mature in their understanding of the subject matter themselves. Emphasis should not be only on the attainment of knowledge, but as well as on skills and abilities in order to obtain and apply knowledge autonomously and meritoriously all through their lives. For that reason, the objective of educational institutions should be to harvest teacher-students who are self-directed and who will employ in lifelong learning. It is essential in any learning environment to do planning to endorse and encourage self-direction in learning. The author is of view that teachers have to commit themselves to self-directed teaching and learning and they need they consequently need to make a learning shift in this meaning-making learning process in which students take the 
initiative, with or without the help of others, in diagnosing the students' learning needs, formulating learning goals, identifying human and material resources for learning, choosing and implementing appropriate learning strategies and evaluating learning outcomes.

\section{Product: Transformative and Holistic Continuing Self-Directed Learning (THCSDL)}

Due to the fact that students' individual learning characteristics are more focused on selfdirected lifelong goal-oriented learning, coupled with a learning environment founded on the pillars of SDL, learning can be seen as a meaning-making change process with the focus on learning as belonging, learning as becoming, learning as experiencing and learning as doing that can lead students to being SDL willing, self-determined in their learning process, more student-mature, autonomous, and competent to apply SDL skills.

The authors' outlook further is that within THCSDL, a transformation is essential: (a) from following learning instructions to doing SDL activities; (b) from memorizing to discovering and incorporating; (c) from listening passively to co-operating and taking responsibility for and ownership of their learning; (d) from giving only knowledge of facts to understanding facts and self-reflecting critically, and (e) from being teacher-dependent to being an independent transformed goal-oriented learner/student. This can cause a change in a student's identity as well as attitude and behaviour towards the importance of SDL.

In education, we need to search for instructive methods that could support students. If SDL is effectively employed by educators, and students' SDL readiness is borne in mind, SDL can be seen to be the casting open of the doors to learning, and should not become a trap in an ever-revolving gate of disappointment and despair. Instruction methods employed by educators in learning environments must therefore ensure that it complements the students' stage of selfdirection towards their readiness, and to support them in developing to be more self-directed over time. When students' level of self-directedness does not match their readiness towards SDL, forcing them into this learning method can cause learning difficulties. Therefore, in such circumstances SDL does hold the potential of harming those students for life.

In addition, students and teachers alike need to continuously engage in SDL, motivated by their personal interest in learning, experience a sense of belonging within SDL, see learning as becoming more self-directed, experience a changed "self", and to be inspired by the supportive SDL learning environment - where students can work without external control, regulate their own learning, work co-operatively, be on the lookout for opportunities to reflect innovatively and develop a self-directed vision. 


\section{SUMMARY}

The proposed theory/model, as presented in Figure 1, projected proposed students' individual learning characteristics and the learning environment as two sets of factors, namely learning as a meaning-making change process factor, and transformative and holistic continuing selfdirected learning as the outcome/product factor. It is important to note that this theory/model presents a linear understanding of component/factor relationships. The interpretation of interactions in this model should include the concept "temporality". That is, in any act of THCSDL, the model/theory does not describe a sequence of fundamental processes stretched over time, but a concurrent presence of students' awareness of the SDL actions in which they are involved.

\section{Hence:}

A precondition for THCSDL is that we need to make meaning of our learning which will simultaneously influence our lives - thus leading to holistic growth. THCSDL needs to be more than simply classroom learning and it needs to connect learning to the student's own life. Individuals need to learn to make their own interpretations as opposed to listening and reacting positively to the beliefs and explanations of others. The goal of education needs to facilitate this understanding rather than provide it. The goal of THCSDL is thus to develop "autonomous thinking", so that the student can become critical of his or her own learning and beliefs and how they affect the way the student makes sense of learning and the world - beyond the formal learning environment. The outcome of THCSDL is that students moreover need to be persistent, have a desire to learn and want to be more self-confident in their learning efforts, enjoy learning, act on their own learning purposes, values, feelings and meanings so as to gain more control over their own learning and lives as socially responsible, clear-thinking and dependable decision makers - rather than simply accepting the purposes, values, feelings and meanings educators have adapted for them.

Therefore we need to foster a mind-set of SDL being fostered in classrooms so that SDL becomes a habit of mind. And so, from the THCSDL development theory, an updated description of SDL can be viewed by the author as:

\footnotetext{
"A meaning-making holistic personal development process transforming students into mature, self-actualized, self-engaged, independent and empowered individuals that have the mind-set of growth, aptitude/capability of taking ownership, authentic control of and accountability for their learning, and in so doing, fostering intellectual openness to evolve into self-directed lifelong goaloriented students.”
} 
Consequently, THCSDL is a process of progressing beyond the act of gaining only factual knowledge to instead becoming holistically changed by what one learns in some meaningful manner. The aim of THCSDL is to establish a process of learning that creates a deep change and transformation in the learning behaviours, -practice, -needs and -attitude of an independent, progressive, personal and holistic growth in an individual within a challenging environment. Hence THCSDL needs to be characterized by a shift in the identity of the student, leading to a process in which the student becomes more capable and/or educated. For this reason, SDL needs to be seen as a habit of mind.

\section{REFERENCES}

Abuhamdeh, S. and M. Csikszentmihalyi. 2012. The importance of challenge for the enjoyment of intrinsically motivated, goal-directed activities. Personality and Social Psychology Bulletin 38: 317-330.

Andruske, C. L. 2009. Self-directed learning: The political act. In Emerging direction in self-directed learning, ed. M. G. Derrick and M. K. Ponton. Chicago, IL: Discovery Association Publishing House.

Biggs, J. B. and C. Tang. 2011. Teaching for quality learning at university. Fourth edition. Berkshire, UK: Open University Press.

Brockett, R. G. 1994. Resistance to self-direction in adult learning: Myths and misunderstandings. New Directions for Continuing Education 64: 5-12.

Brockett, R. G. and R. Hiemstra. 1991. Self-direction in adult learning: Perspectives on theory, research, and practice. London, England and New York, NY: Routledge. http://www-distance. syr.edu/sdlindex.html (Accessed 12 June 2016).

Brockett, R. G., S. L. Stockdale, D. L. Fogerson, B. F. Cox, J. B. Canipe, L. A. Chuprina, R. C. Donaghy and N. E. Chadwell. 2001. Two decades of self-directed learning: A content analysis. Presented at the 14th annual International Self-Directed Learning Symposium, Boynton Beach, FL. (ERIC Document Reproduction Service No. ED 449 348). http://eric.ed.gov/PDFS/ED449348.pdf (Accessed 12 June 2016).

Brookfield, S. D. 1993. Self-directed learning, political clarity, and the critical practice of adult education. Adult Education Quarterly 43(4): 227-242.

Brookfield, S. 2005. The power of critical theory: Liberating adult learning and teaching. San Francisco: Jossey-Bass.

Caffarella, R. S. 1993. Self-directed learning. In An update on adult learning theory, ed. S. B. Merriam. New Directions for Adult and Continuing Education No. 57. San Francisco, CA: Jossey-Bass.

Candy, P. C. 1991. Self-direction for lifelong education. San Francisco, CA: Jossey-Bass.

Canipe, J. B and D. L. Fogerson. 2006. The literature of self-directed learning: Dissertations. International Journal of Self-directed Learning 3(2) Fall.

Chang, S. M. 2012. The effect of specific goals on EFL students' self-efficacy and performance on vocabulary learning. NCUE Journal of Humanities 5(1): 53-74.

Conner, T. R., S. L. Carter, V. Dieffenderfer and R. G. Brockett. 2009. A citation analysis of selfdirected learning literature, 1980-2008. International Journal of Self-Directed Learning 6(2): 5375.

Du Toit-Brits, C. 2015. Endowing self-directed learning in learning environments: Interrelated connection between students' environments and self-directed preparedness. Journal of Education Studies Special Issue (2015): 32-52. 
Du Toit-Brits, C. and C. van Zyl. 2017. Embedding motivation in the self-directedness of first-year teacher students. South African Journal of Higher Education 31(1): 50-65.

Entwistle, N. and A. Entwistle. 1997. Revision and experience of understanding. In The experience of learning. Implications for teaching and studying in higher education, ed. F. Marton., D. Hounsell and N. Entwistle, 146-158. Second edition. Edinburgh: Scottish Academic Press.

Entwistle, N. J. 1991. Approaches to learning and perceptions of the learning environment. Introduction to the special issue. Higher Education 22: 201-204.

Garrison, D. R. 1997. Self-directed learning: Toward a comprehensive model. Adult Education Quarterly 48(1): 18-33.

Garrison, D. R and M. Baynton. 1987. Beyond independence in distance education: The concept of control. The American Journal of Distance Education 1(3): 3-15.

Guglielmino, L. M. 1978. Development of the self-directed learning readiness scale. Doctoral dissertation, University of Georgia, 1977. Dissertation abstracts international 38: 6467A.

Guglielmino, L. M. 2008. Why self-directed learning? International Journal of Self-Directed Learning 5(1): 1-14.

Gabrielle, D. M., L. M. Guglielmino and P. J. Guglielmino. 2006. Developing self-directed learning readiness of future leaders in a military college through instructional innovation. International Journal of Self-Directed Learning 3(1): 24-35. http://sdlglobal.com /journals.php (Accessed 7 March 2017).

Guglielmino, L. M. 2013. The case for promoting self-directed learning in formal educational institutions. SA-eDUC Journal 10(2): 1-18.

Gow, L. and D. Kember. 1993. Conceptions of teaching and their relationship to student learning. British Journal of Educational Psychology 63: 20-33.

Grow, G. O. 1991. Teaching learners to be self-directed. Adult Education Quarterly 41(3): 125-149.

Hammond, M. and R. Collins. 1991. Self-directed learning: Critical practice. London: Kogan Page.

Hiemstra, R. 1994. Self-directed learning. In The International Encyclopaedia of Education, ed. T. Husen and T. N. Postlethwaite. Second edition. Oxford: Pergamon Press.

Hiemstra, R. (Ed.). 1991. Creating environments for effective adult learning. New Directions for Adult and Continuing Education No 50. San Francisco, CA: Jossey-Bass.

Hiemstra, R. and B. Sisco. 1990. Individualizing instruction: Making learning personal, empowering, and successful. San Francisco: Jossey-Bass. http://www-distance.syr.edu/iiindex.html (Accessed 12 June 2012).

Holt, L. L. 2011. Self-direction and technology use among new workforce entrants. Unpublished doctoral dissertation. University of Tennessee, Knoxville. http://trace.tennessee.edu/ utk_graddiss $/ 1191$

Johnson, A. P. 2012. Humanistic and holistic learning theory. http://teacher-strategies.homestead. com/Ch_9_humanistic_holistic_1_.pdf (Accessed 24 January 2017).

Kember, D. and D. Y. P. Leung. 2009. Development of a questionnaire for assessing students' perceptions of the teaching and learning environment and its use in quality assurance. Learning Environments Research 12(1): 15-29.

Khiat, H. 2015. Academic performance and the practice of self-directed learning: The adult student perspective. Journal of Further and Higher Education. DOI: 10.1080/0309877X.2015.1062849

Kirk, J. M., C. K. Shih, B. C. Smeltzer, L. L. Holt and R. G. Brockett. 2012. A citation analysis of the International Journal of Self-Directed Learning. Presented at the 26th annual International SelfDirected Learning Symposium, Cocoa Beach, FL.

Knowles, M. 1975. Self-directed learning: A guide for learners and teachers. Chicago: Follett Publishing Company.

Knowles, M. S., E. F. Holton III and A. Swanson. 2015. The adult learner. The definitive classic in adult 
education and human resource development. $8^{\text {th }}$ Edition. London and New York: Routledge Taylor \& Francis Group.

Long, H. B. 1998. Theoretical and practical implications of selected paradigms of self-directed learning. In Developing paradigms for self-directed learning, ed. H. B. Long. University of Oklahoma: College of Education.

Mezirow, J. 2000. Learning to think like an adult. Core concepts of transformation theory. In The Handbook of transformative learning: Theory, research and practise, ed. J. Mezirow and Associates, 35-70. San Francisco, CA:Jossey-Bass.

Merriam, S. B. 2001. Andragogy and self-directed learning: Pillars of adult learning theory. In The new update on adult learning theory, ed. S. B. Merriam, 3-13. New Directions for Adult and Continuing Education No. 89. San Francisco, CA: Jossey-Bass.

Merriam, S. B., R. S. Caffarella and L. M. Baumgartner. 2007. Learning in adulthood: A comprehensive guide. San Francisco: Jossey-Bass.

Oddi, L. F., A. J. Ellis and J. E. Roberson. 1990. Construct validation of the Oddi Continuing Learning Inventory. Adult Education Quarterly 40(3): 139-145.

Owen, T. R. 2002. Self-directed learning in adulthood: A literature review. ERIC Document Reproduction Service, No. ED 461-050.

Pappas, C. 2013. The adult learning theory - Andragogy - of Malcolm Knowles. eLearning industry. instructional design. https://elearningindustry.com/the-adult-learning-theory-andragogy-ofmalcolm-knowles (Accessed 12 January 2017).

Peters, J. M. 1989. Self-direction and problem solving: Theory and method. In Self-directed learning: Emerging theory and practice, ed. H. B. Long. University of Oklahoma: Oklahoma Research Center for Continuing Professional and Higher Education.

Ramsden, P. 2003. Learning to teach in higher education. London: Routledge Falmer.

Rager, K. 2004. A thematic analysis of the self-directed learning experiences of 13 breast cancer patients. International Journal of Lifelong Education 23(1): 95-109.

Trigwell, K. and P. Prosser. 1996. Changing approaches to teaching: A relational perspective. Studies in Higher Education 21: 275-284.

Trigwell, K., M. Prosser and F. Waterhouse. 1999. Relations between teachers' approaches to teaching and students' approaches to learning. Higher Education 37: 57-70.

Wenger, E. 1998. Communities of practice: Learning, meaning, and identity. Cambridge, MA: Harvard University Press.

Wertsch, J. 1985. Vygotsky and the social formation of mind. Cambridge, MA: Harvard University Press. 